\title{
RB's original CIN?
}

\author{
Julien Sage ${ }^{1,2,4}$ and Aaron F. Straight ${ }^{3,5}$ \\ ${ }^{1}$ Department of Pediatrics, Stanford University, Stanford, California 94305, USA; ${ }^{2}$ Department of Genetics, Stanford University, \\ Stanford, California 94305, USA; ${ }^{3}$ Department of Biochemistry, Stanford University, Stanford, California 94305, USA
}

The retinoblastoma tumor suppressor $\mathrm{RB}$ is the downstream mediator of a cellular pathway that is thought to prevent cancer by controlling the ability of cells to enter or exit the cell cycle in G0/G1. Recently, however, accumulating evidence has suggested that $R B$, its family members p107 and p130, and their partners, the E2F family of transcription factors, may have important cellular functions beyond the G1/S transition of the cell cycle, including during DNA replication and at the transition into mitosis. In this issue of Genes \& Development, three studies demonstrate a critical role for $\mathrm{RB}$ in proper chromosome condensation, centromeric function, and chromosome stability in mammalian cells, and link these cellular functions of RB to tumor suppression in mice. Here we discuss how transcriptional and posttranscriptional mechanisms under the control of the RB pathway ensure accurate progression through mitosis, thereby preventing cancer development.

The RB tumor suppressor was first identified in familial cases of retinoblastoma, a pediatric cancer of the eye. $R B$ was then found to be mutated in a large number of human tumors, including osteosarcoma; small-cell lung carcinoma; and breast, bladder, or prostate cancers. When $R B$ itself is not mutated in human cancer cells, these cells nearly always carry alterations in upstream regulators of $\mathrm{RB}$ function, such as the p16 ${ }^{\text {Ink4a }}$ cell cycle inhibitor or the CyclinD/Cdk4,6 kinase complexes. A vast number of experiments have assigned a potent role for the RB pathway at the $\mathrm{G} 1 / \mathrm{S}$ transition of the cell cycle, and provide a model to explain why loss of RB function may lead to cancer: In G0/G1, RB is mostly hypophosphorylated, and is able to bind and control the expression of critical cell cycle genes by interacting with E2F transcription factors and chromatin remodeling complexes; as cells enter the cell cycle, RB becomes inactivated by phosphorylation, allowing E2F to transactivate the expression of genes essential for DNA replication and cell cycle progression. $\mathrm{RB}$ inactivation in cancer cells by direct mutation or con-

[Keywords: Chromosome instability; centromere; chromosome condensation; cell cycle; $\mathrm{Rb}$; sister chromatid cohesion]

Corresponding authors.

${ }^{4}$ E-MAIL julsage@stanford.edu; FAX (650) 736-0195.

${ }^{5}$ E-MAIL astraigh@stanford.edu; FAX (650) 723-6783.

Article published online ahead of print. Article and publication date are online at http://www.genesdev.org/cgi/doi/10.1101/gad.1948010. stitutive hyperphosphorylation leads to loss of an important checkpoint at the G1/S transition of their cell cycle, and mutant cells proliferate even under cytostatic conditions. This model explains why the RB pathway is such a strong tumor suppressor pathway, but it does not exclude that RB has other tumor suppressor activities; for instance, RB may also directly promote differentiation, which could play a role in inhibiting cancer development (for review, see Burkhart and Sage 2008).

Loss of RB function and chromosomal instability (CIN)

Human tumor cells often show signs of genomic instability (Negrini et al. 2010). Accumulating evidence has indicated that loss of RB function may play a role in this process; for example, by inducing defects during the replication of DNA, and potentially by causing abnormal segregation of chromosomes during mitosis (Kennedy et al. 2000; Foijer et al. 2005; Eguchi et al. 2007). Embryonic stem cells (ESCs), which are largely devoid of a G1 checkpoint, provide a good system to investigate a potential role for the RB pathway in G2/M /Conklin and Sage 2009). Deletion of both $R B$ alleles in mouse ESCs results in increased chromosomal alterations (Zheng et al. 2002). In mouse embryonic fibroblasts (MEFs), $R B$ inactivation leads to polyploidy (Srinivasan et al. 2007). In mouse hepatocytes, loss of $R B$ function promotes aneuploidy (Mayhew et al. 2005). Similarly, knockdown of $R B$ in human primary cells promotes aneuploidy via micronuclei formation (Amato et al. 2009).

Interestingly, several studies, including the analysis of gene expression profiles, have identified E2F target genes involved not only in the G1/S transition and DNA replication, but also in DNA repair, in G2, and during mitosis in mammalian cells (Ishida et al. 2001; Ren et al. 2002; Polager and Ginsberg 2003). The regulation of G2/M genes by E2F may be further induced in cells under genotoxic stress (Eguchi et al. 2007; Plesca et al. 2007). Different E2F family members may play different roles in this process, and they interact functionally with other specific transcription factors in G1/S and G2/M (Zhu et al. 2004). Among all these potential targets, the regulation of the expression of the mitotic checkpoint component MAD2 by RB/E2F transcriptional regulators has been shown to play an important role in the control of chromosomal stability (Fig. 1; Hernando et al. 2004). MAD2 normally prevents cell cycle progression by 
blocking activation of the key E3 ubiquitin ligase, the anaphase-promoting complex (APC), which ubiquitylates Cyclin proteins and the chromosome cohesion regulator Securin. In the absence of APC activity, Cyclins and Securin remain stable, and cells arrest in metaphase until the mitotic checkpoint is satisfied. Overexpression of MAD2 is sufficient to induce CIN and cancer in mice (Sotillo et al. 2007). Related to the transcriptional control of Mad2 levels by RB/E2F complexes, the control of the expression of other negative regulators of APC activity, Emi1 and BubR1, by E2F (Hsu et al. 2002; Lehman et al. 2007) indicates that both increased E2F-mediated transcription and inappropriate protein stability may cooperate in the genomic instability downstream from loss of $\mathrm{RB}$ function.

In addition to its role in regulating the transcription of specific genes important for G2 and M, RB may prevent genomic instability by controlling the expression of chromatin- and DNA-modifying enzymes themselves (McCabe et al. 2005; Siddiqui et al. 2007), and by directly influencing chromatin structure, including in centromeric and telomeric regions; for instance, $\mathrm{RB}$ directly binds the histone H4 Lys 20 (H4K20) methyltransferases SUV4-2OH1 and SUV4-20H2, and is thought to recruit those enzymes to pericentric heterochromatin to maintain pericentric histone $\mathrm{H} 4$ methylation (Gonzalo and Blasco 2005; Isaac et al. 2006; Siddiqui et al. 2007). Loss of SUV4-20H1,2 activity has been associated with increased frequencies of telomere recombination (Benetti et al. 2007), and loss of H4K20 methylation in general has been connected to chromosome condensation defects, G2/M checkpoint arrest, and DNA damage (Heit et al. 2009; Oda et al. 2009), but a direct link between RB loss, loss of these methylation marks, and CIN is still missing.

While these observations have provided strong support for a role of the $\mathrm{RB}$ pathway in the maintenance of chromosomal stability, the exact mechanisms underlying this role are still poorly understood, and a direct link be- tween loss of RB function, increased instability, and cancer has not been clearly demonstrated. Three studies published in this issue of Genes \& Development (Coschi et al. 2010; Manning et al. 2010; van Harn et al. 2010) now provide novel mechanistic advances regarding the role of $\mathrm{RB}$ in the maintenance of chromosomal stability and cancer prevention.

\section{Accumulation of DNA damage and CIN in RB family mutant cells under stress conditions}

In mammalian cells, RB belongs to a family of structurally and functionally related proteins with p107 and p130. Combined deletion of the three $R B$ family genes in MEFs blocks the ability of these triple-knockout (TKO) cells to arrest in G1 (Dannenberg et al. 2000; Sage et al. 2000). Hein te Riele and colleagues (van Harn et al. 2010) had already shown that TKO MEFs expressing Bcl2 (to prevent apoptotic cell death) arrest in G2 after serum deprivation; this arrest is transient, and the cells can complete their cell cycle upon serum stimulation (Foijer et al. 2005). van Harn et al. (2010) took this observation one step further, and found that inhibition of the sensor of DNA damage, ATM, accelerated mitotic entry of serumstimulated TKO-Bcl2 MEFs that were arrested in G2, suggesting that a DNA damage response was slowing cell cycle re-entry in G2. Indeed, G2-arrested TKO-Bcl2 MEFs displayed an increase in the presence of DNA doublestrand breaks (DSBs) compared with cycling controls. Furthermore, some DSBs persisted after mitosis, indicating that TKO cells did not fully repair the damage to their DNA before re-entering the cell cycle. van Harn et al. (2010) then analyzed the chromosomes of TKO-Bcl2 MEFs that had been arrested in G2 in low serum and then had resumed proliferation in full serum. They found that these mutant cells displayed chromatid breaks, railroad chromosomes, and loss of tight centromeric cohesion. Clones derived from these cells were analyzed by

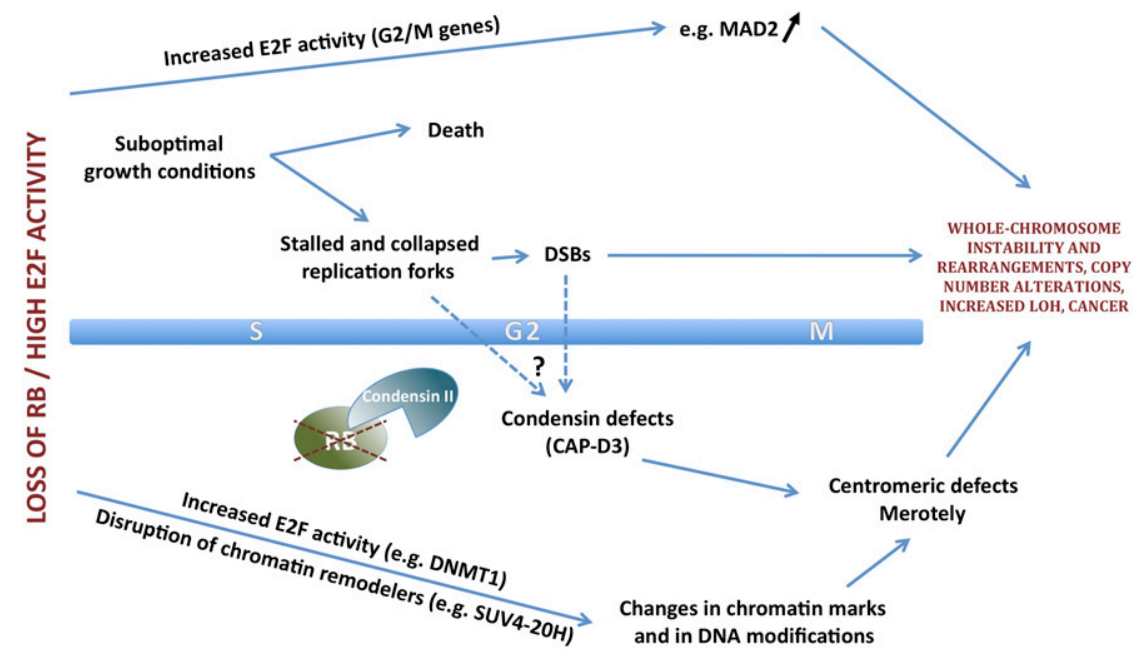
a complex regulatory network of transcriptional and post-transcriptional elements by which the RB pathway controls chromosomal stability at the G2/M transition of the cell cycle.

Figure 1. Loss of RB function triggers CIN by several mechanisms. Inactivation of $\mathrm{RB}$ and its family members, p107 and p130, results in deregulated activation of E2F transcription factors. Targets of E2F include MAD2, a critical regulator of the spindle assembly checkpoint in mitosis, as well as enzymes that modify the structure of the DNA, such as the DNMT1 methyltransferase. In addition, loss of RB function may alter the activity of some of its binding partners involved in the control of chromatin structure, such as SUV4-20H. Similarly, loss of RB affects the function of complexes, such as condensin II complexes, involved in mitotic chromosome assembly. Finally, loss of RB family function may lead to the accumulation of DSBs due to defects during DNA replication, including under stress conditions. Altogether, this defines stability at the G2/M transition of the cell cycle. 
array comparative genomic hybridization (aCGH) and multiplex FISH (M-FISH), showing that copy number alterations (CNAs) were increased compared with control cells (van Harn et al. 2010).

Together, these studies provide convincing evidence that, in mitogen-deprived conditions, TKO-Bcl2 MEFs exhibit an increase in DSBs that are not fully repaired before these cells divide, which eventually leads to CIN when cells are allowed to re-enter the cell cycle. In the model proposed by van Harn et al. (2010), cells with alterations in pathways controlling the G1/S transition of the cell cycle and cell survival may accumulate genomic instability, providing a mechanism for cancer progression (Fig. 1). Studies in Schizosaccharomyces pombe have shown that H4K20 methylation is important for recruiting the DNA damage checkpoint response protein Crb2 to sites of DSBs, but that loss of H4K20 does not affect pericentric heterochromatin as it does in vertebrates (Sanders et al. 2004). It will be interesting to determine whether the DNA damage phenotypes in TKO-Bcl2 cells are analogous to the phenotypes seen in $S$. pombe, whether stalled or collapsed DNA replication forks or the DSBs that result from replication defects are directly linked to the chromosome cohesion defects observed in the mutant cells, or whether cohesion defects arise from alternative functions of RB.

\section{Centromeric dysfunction in RB mutant human cells}

Data from van Harn et al. (2010) with RB/p107 doublemutant MEFs suggest that the G2/M defects observed in TKO cells may exist in cells in which the function of only one or two family members is abrogated, but $R B$-deficient MEFs arrest in G1 upon serum removal, preventing the analysis of its role in CIN in the assay developed by these investigators. In contrast, recent experiments in Drosophila and human cells with only mutations in $R B$ indicate that RB may normally promote chromosomal condensation and preserve chromosomal stability through an interaction with condensin II complexes (Longworth et al. 2008). Nick Dyson and colleagues (Manning et al. (2010) pursued this analysis, and investigated the consequences of depleting RB function in human RPE-1 cells for centromere function and chromosomal stability. Confirming the findings in TKO MEFs, this analysis in human cells shows that $R B$ knockdown causes a significant increase in chromosome missegregation, as measured by FISH, at a rate similar to what is seen in human tumor cell lines with a CIN phenotype. In a series of elegant experiments, Manning et al. (2010) dissected the mitotic phenotypes of $R B$ knockdown cells; they found that the mutant cells have a higher mitotic index with more cells in prometaphase despite a normal spindle checkpoint and no signs of centrosome overduplication. In contrast, they observed increased intercentromeric distance, defects in chromosomal alignment in a tight metaphase plate, bioriented sister kinetochores that often deviate from the pole-to-pole axis, and premature loss of sister chromatid cohesion, especially when cells were delayed in mitosis, similar to the study in TKO MEFs. Together, these observations led Manning et al. (2010) to further explore centromeric defects in $R B$ mutant cells.

Similar to what was observed in TKO MEFs, loss of RB in RPE-1 cells did not affect the levels of the cohesin protein RAD21 (Peters et al. 2008). However, RAD21 punctate pattern on the DNA was decreased in $R B$ knockdown cells after nuclear envelope breakdown. The same observation was made in polytene chromosomes of $R B$ mutant flies. Lack of evidence for increased RAD21 cleavage suggested that these defects are probably loading or maintenance defects of cohesin at the centromere, rather than excessive removal. Furthermore, Manning et al. (2010) found that the amount of chromatin-associated CAP-D3 condensin was reduced in $R B$ knockdown cells, especially at the centromere. Cells depleted of $R B$ or $C A P-D 3$ by siRNA showed a similar increase in intercentromeric distance (Fig. 1; Manning et al. 2010). A particularly interesting aspect of this study is the fact that the phenotypes of loss of RB function are subtle, still allowing the mutant cells to divide while accumulating instability, providing a mechanism for the development of cancer upon loss of RB function.

\section{Cancer development due to CIN in RB mutant cells}

Preliminary evidence provided by van Harn et al. (2010) suggests that the arrest in G2 and the re-entry with unrepaired DNA in TKO MEFs may be a step toward cancerous transformation in Ras transformation assays. However, this study (van Harn et al. 2010) and the study from the Dyson group (Manning et al. 2010) did not directly address whether the genomic instability resulting from loss of RB function is linked to cancer development.

RB binds to several chromatin modifiers through the LXCXE-binding domain, and recent evidence by Fred Dick and colleagues (Coschi et al. 2010) has demonstrated that an LXCXE-binding mutant that retains E2F-binding capability still contributes to CIN through its failure to regulate appropriate pericentric heterochromatin formation (Isaac et al. 2006). Coschi et al. (2010) further examined this mutant allele of $R B(\Delta \mathrm{L})$ and evaluated its role in tumorigenesis. They first examined mitotic events in wild-type and $R B^{\Delta L / \Delta L}$ mutant MEFs and ESCs and found an increase in centromere interactions, delayed chromosome condensation, abnormal metaphase, and lagging chromosomes in the mutant cells. Because these defects were reminiscent of defects in chromosome condensation and/or cohesion, Coschi et al. (2010) measured the protein levels of the components of the condensin and cohesin complexes. Similar to what Manning et al. (2010) had observed in $R B$ mutant human cells, Coschi et al. (2010) found decreased levels of chromatin-associated condensin II in the $R B^{\Delta \mathrm{L}}$ mutant cells. Depletion of the condensin II subunit CAP-D3 resulted in defects similar to those observed in $\Delta \mathrm{L}$ mutant cells, and similar to what had been shown previously in different cell types (Ono et al. 2003; Hirota et al. 2004). In addition, the $\Delta \mathrm{L}$ form of RB was not able to interact with CAP-D3, suggesting a functional link between RB and condensin II complexes (Fig. 1). Then Manning et al. (2010) tested the functional role of the $\Delta \mathrm{L}$ 
allele in cancer in the context of $p 53$ deficiency. Doublemutant mice died faster than p53 mutant mice, with more tumors that were more aggressive and more metastatic. Interestingly, double-mutant thymic lymphomas display increased genomic instability compared with $p 53$ mutant tumors. Furthermore, $p 53^{+/-} ; R B^{\Delta L / \Delta L}$ mutant mice died faster than $p 53^{+/-}$mice, suggesting that the $\Delta \mathrm{L}$ allele leads to faster loss of the wild-type $p 53$ allele, and providing a mechanism for the accumulation of genomic instability and tumor progression in $R B$ mutant cells.

\section{Conclusions and future directions}

A number of studies on the mechanisms of action of cohesin and condensin complexes, and more generally on the molecular mechanisms ensuring progression through G2 and M, have been performed in tumor cell lines in which the function of the RB family of proteins pathway is nearly always compromised. The data presented in Coschi et al. (2010), Manning et al. (2010), and van Harn et al. (2010) showing a role for RB in the control of condensin II complexes and CIN raise the question of whether these experiments have given a full and accurate description of the cellular functions of these complexes.

These studies also open new avenues of research in the RB field. First, the direct binding partner(s) of RB in the condensin II complexes remain to be identified. Second, $R B$ 's role for condensin II recruitment seems to be transferred to protein phosphatase II A (PP2A) once cells are in metaphase (Takemoto et al. 2009). Understanding the relationship between these two mechanisms for condensin recruitment provides an interesting avenue for further study. Third, loss of RB function and condensin recruitment is likely to contribute to CIN by perturbing centromere structure and inducing merotelic kinetochore attachment, an important cause of CIN in tumor cells (Fig. 1; Salmon et al. 2005; Cimini 2008; Samoshkin et al. 2009). However, the relationship between RB and sister chromatid cohesion is still unclear, given that the known phenotypes of condensin mutations, with the exception of an increased distance between sister centromeres in mitosis, do not exactly mimic known sister chromatid cohesion mutants. In vertebrate systems, condensin II does not appear to play a major role in centromere cohesion, while condensin I is important for the resolution of sister chromosome arms (Ono et al. 2003; Hirota et al. 2004). In Drosophila, condensin complexes are important for sister chromosome resolution, and defects in condensin function lead to chromosome missegregation (Coelho et al. 2003; Dej et al. 2004; Savvidou et al. 2005). In this context, loss of condensin function would not be predicted to cause premature chromosome separation, but to inhibit the proper separation of sister chromatids, and this is the primary phenotype observed in metazoan condensin mutant cells (for review, see Hudson et al. 2009). Thus, one interesting possibility that can be tested in future studies is that the cohesion defects seen by Coschi et al. (2010), Manning et al. (2010), and van Harn et al. (2010) in $R B$ mutant cells represent an alternative pathway that is at least partly independent of condensin II recruitment to chromosomes, and instead is more directly related to cohesin function. Coschi et al. (2010), Manning et al. (2010), and van Harn et al. (2010) demonstrated that $\mathrm{RB}$ disruption did not dramatically alter cohesin binding to chromatin; future experiments to determine if the chromatin-bound cohesin in RB mutant cells is productively mediating chromosome cohesion will likely provide important insights into RB-dependent cohesion phenotypes and RB's role in the prevention of CIN.

\section{Acknowledgments}

We thank Jamie Conklin for helpful discussions on the manuscript. We also apologize to our colleagues whose work was not cited due space limitations. The work in J.S.'s laboratory is supported by NIH/NCI grant R01 CA114102-01A1, ACS grant RSG10-071-01-TBG, and CIRM grant RB1-01385. The work in A.F.S's laboratory is supported by grant GM074728 from the NIH.

\section{References}

Amato A, Lentini L, Schillaci T, Iovino F, Di Leonardo A. 2009. RNAi mediated acute depletion of retinoblastoma protein $(\mathrm{pRb})$ promotes aneuploidy in human primary cells via micronuclei formation. BMC Cell Biol 10: 79. doi: 10.1186/ 1471-2121-10-79.

Benetti R, Gonzalo S, Jaco I, Schotta G, Klatt P, Jenuwein T, Blasco MA. 2007. Suv4-20h deficiency results in telomere elongation and derepression of telomere recombination. J Cell Biol 178: 925-936.

Burkhart DL, Sage J. 2008. Cellular mechanisms of tumour suppression by the retinoblastoma gene. Nat Rev Cancer 8: 671682.

Cimini D. 2008. Merotelic kinetochore orientation, aneuploidy, and cancer. Biochim Biophys Acta 1786: 32-40.

Coelho PA, Queiroz-Machado J, Sunkel CE. 2003. Condensindependent localisation of topoisomerase II to an axial chromosomal structure is required for sister chromatid resolution during mitosis. J Cell Sci 116: 4763-4776.

Conklin JF, Sage J. 2009. Keeping an eye on retinoblastoma control of human embryonic stem cells. J Cell Biochem 108: 1023-1030.

Coschi $\mathrm{CH}$, Martens AL, Ritchie K, Francis SM, Chakrabarti S, Berube NG, Dick FA. 2010. Mitotic chromosome condensation mediated by the retinoblastoma protein is tumor-suppressive. Genes Dev (this issue). doi: 10.1101/gad.1917610.

Dannenberg JH, van Rossum A, Schuijff L, te Riele H. 2000. Ablation of the retinoblastoma gene family deregulates $\mathrm{G}(1)$ control causing immortalization and increased cell turnover under growth-restricting conditions. Genes Dev 14: 30513064.

Dej KJ, Ahn C, Orr-Weaver TL. 2004. Mutations in the Drosophila condensin subunit dCAP-G: Defining the role of condensin for chromosome condensation in mitosis and gene expression in interphase. Genetics 168: 895-906.

Eguchi T, Takaki T, Itadani H, Kotani H. 2007. RB silencing compromises the DNA damage-induced G2/M checkpoint and causes deregulated expression of the ECT2 oncogene. Oncogene 26: 509-520.

Foijer F, Wolthuis RM, Doodeman V, Medema RH, te Riele H. 2005. Mitogen requirement for cell cycle progression in the absence of pocket protein activity. Cancer Cell 8: 455-466.

Gonzalo S, Blasco MA. 2005. Role of Rb family in the epigenetic definition of chromatin. Cell Cycle 4: 752-755. 
Heit R, Rattner JB, Chan GK, Hendzel MJ. 2009. G2 histone methylation is required for the proper segregation of chromosomes. J Cell Sci 122: 2957-2968.

Hernando E, Nahle Z, Juan G, Diaz-Rodriguez E, Alaminos M, Hemann M, Michel L, Mittal V, Gerald W, Benezra R, et al. 2004. $\mathrm{Rb}$ inactivation promotes genomic instability by uncoupling cell cycle progression from mitotic control. Nature 430: $797-802$.

Hirota T, Gerlich D, Koch B, Ellenberg J, Peters JM. 2004. Distinct functions of condensin I and II in mitotic chromosome assembly. J Cell Sci 117: 6435-6445.

Hsu JY, Reimann JD, Sorensen CS, Lukas J, Jackson PK. 2002. E2F-dependent accumulation of hEmil regulates $S$ phase entry by inhibiting APC(Cdh1). Nat Cell Biol 4: 358-366.

Hudson DF, Marshall KM, Earnshaw WC. 2009. Condensin: Architect of mitotic chromosomes. Chromosome Res 17: 131-144.

Isaac CE, Francis SM, Martens AL, Julian LM, Seifried LA, Erdmann N, Binne UK, Harrington L, Sicinski P, Berube NG, et al. 2006. The retinoblastoma protein regulates pericentric heterochromatin. Mol Cell Biol 26: 3659-3671.

Ishida S, Huang E, Zuzan H, Spang R, Leone G, West M, Nevins JR. 2001. Role for E2F in control of both DNA replication and mitotic functions as revealed from DNA microarray analysis. Mol Cell Biol 21: 4684-4699.

Kennedy BK, Barbie DA, Classon M, Dyson N, Harlow E. 2000. Nuclear organization of DNA replication in primary mammalian cells. Genes Dev 14: 2855-2868.

Lehman NL, Tibshirani R, Hsu JY, Natkunam Y, Harris BT, West RB, Masek MA, Montgomery K, van de Rijn M, Jackson PK. 2007. Oncogenic regulators and substrates of the anaphase promoting complex/cyclosome are frequently overexpressed in malignant tumors. Am J Pathol 170: 1793-1805.

Longworth MS, Herr A, Ji JY, Dyson NJ. 2008. RBF1 promotes chromatin condensation through a conserved interaction with the Condensin II protein dCAP-D3. Genes Dev 22: 1011-1024.

Manning AL, Longworth MS, Dyson NJ. 2010. Loss of pRB causes centromere dysfunction and chromosomal instability. Genes Dev (this issue). doi: 10.1101/gad.1917310.

Mayhew CN, Bosco EE, Fox SR, Okaya T, Tarapore $\mathrm{P}$, Schwemberger SI, Babcock GF, Lentsch AB, Fukasawa K, Knudsen ES. 2005. Liver-specific pRB loss results in ectopic cell cycle entry and aberrant ploidy. Cancer Res 65: 4568-4577.

McCabe MT, Davis JN, Day ML. 2005. Regulation of DNA methyltransferase 1 by the pRb/E2F1 pathway. Cancer Res 65: 3624-3632.

Negrini S, Gorgoulis VG, Halazonetis TD. 2010. Genomic instability-An evolving hallmark of cancer. Nat Rev Mol Cell Biol 11: 220-228.

Oda H, Okamoto I, Murphy N, Chu J, Price SM, Shen MM, Torres-Padilla ME, Heard E, Reinberg D. 2009. Monomethylation of histone H4-lysine 20 is involved in chromosome structure and stability and is essential for mouse development. Mol Cell Biol 29: 2278-2295.

Ono T, Losada A, Hirano M, Myers MP, Neuwald AF, Hirano T. 2003. Differential contributions of condensin I and condensin II to mitotic chromosome architecture in vertebrate cells. Cell 115: 109-121.

Peters JM, Tedeschi A, Schmitz J. 2008. The cohesin complex and its roles in chromosome biology. Genes Dev 22: 3089-3114.

Plesca D, Crosby ME, Gupta D, Almasan A. 2007. E2F4 function in G2: Maintaining G2-arrest to prevent mitotic entry with damaged DNA. Cell Cycle 6: 1147-1152.

Polager S, Ginsberg D. 2003. E2F mediates sustained G2 arrest and down-regulation of Stathmin and AIM-1 expression in response to genotoxic stress. I Biol Chem 278: 1443-1449.
Ren B, Cam H, Takahashi Y, Volkert T, Terragni J, Young RA, Dynlacht BD. 2002. E2F integrates cell cycle progression with DNA repair, replication, and $\mathrm{G}(2) / \mathrm{M}$ checkpoints. Genes Dev 16: 245-256.

Sage J, Mulligan GJ, Attardi LD, Miller A, Chen S, Williams B, Theodorou E, Jacks T. 2000. Targeted disruption of the three Rb-related genes leads to loss of G(1) control and immortalization. Genes Dev 14: 3037-3050.

Salmon ED, Cimini D, Cameron LA, DeLuca JG. 2005. Merotelic kinetochores in mammalian tissue cells. Philos Trans $R$ Soc Lond B Biol Sci 360: 553-568.

Samoshkin A, Arnaoutov A, Jansen LE, Ouspenski I, Dye L, Karpova T, McNally J, Dasso M, Cleveland DW, Strunnikov A. 2009. Human condensin function is essential for centromeric chromatin assembly and proper sister kinetochore orientation. PLoS One 4: e6831. doi: 10.1371/journal.pone. 0006831.

Sanders SL, Portoso M, Mata J, Bahler J, Allshire RC, Kouzarides T. 2004. Methylation of histone H4 lysine 20 controls recruitment of Crb2 to sites of DNA damage. Cell 119: 603-614.

Savvidou E, Cobbe N, Steffensen S, Cotterill S, Heck MM. 2005. Drosophila CAP-D2 is required for condensin complex stability and resolution of sister chromatids. J Cell Sci 118: 2529-2543.

Siddiqui H, Fox SR, Gunawardena RW, Knudsen ES. 2007. Loss of RB compromises specific heterochromatin modifications and modulates HP1 $\alpha$ dynamics. J Cell Physiol 211: 131-137.

Sotillo R, Hernando E, Diaz-Rodriguez E, Teruya-Feldstein J, Cordon-Cardo C, Lowe SW, Benezra R. 2007. Mad2 overexpression promotes aneuploidy and tumorigenesis in mice. Cancer Cell 11: 9-23.

Srinivasan SV, Mayhew CN, Schwemberger S, Zagorski W, Knudsen ES. 2007. RB loss promotes aberrant ploidy by deregulating levels and activity of DNA replication factors. J Biol Chem 282: 23867-23877.

Takemoto A, Maeshima K, Ikehara T, Yamaguchi K, Murayama A, Imamura S, Imamoto N, Yokoyama S, Hirano T, Watanabe $\mathrm{Y}$, et al. 2009. The chromosomal association of condensin II is regulated by a noncatalytic function of PP2A. Nat Struct Mol Biol 16: 1302-1308.

van Harn T, Foijer F, van Vugt M, Banerjee R, Yang F, Oostra A, Joenje $\mathrm{H}$, te Riele $\mathrm{H}$. 2010. Loss of $\mathrm{Rb}$ proteins causes genomic instability in the absence of mitogenic signaling. Genes Dev (this issue). doi: 10.1101/gad.580710.

Zheng L, Flesken-Nikitin A, Chen PL, Lee WH. 2002. Deficiency of Retinoblastoma gene in mouse embryonic stem cells leads to genetic instability. Cancer Res 62: 2498-2502.

Zhu W, Giangrande PH, Nevins JR. 2004. E2Fs link the control of G1/S and G2/M transcription. EMBO J 23: 4615-4626. 


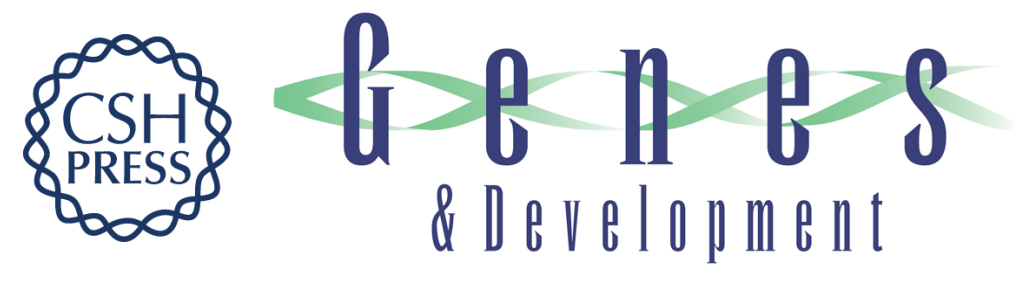

\title{
RB's original CIN?
}

\author{
Julien Sage and Aaron F. Straight
}

Genes Dev. 2010, 24: originally published online June 15, 2010

Access the most recent version at doi:10.1101/gad.1948010

\section{Related Content Mitotic chromosome condensation mediated by the retinoblastoma protein is tumor-suppressive \\ Courtney H. Coschi, Alison L. Martens, Kieran Ritchie, et al. \\ Genes Dev. July, 2010 24: 1351-1363 Loss of pRB causes centromere dysfunction and chromosomal instability \\ Amity L. Manning, Michelle S. Longworth and Nicholas J. Dyson \\ Genes Dev. July, 2010 24: 1364-1376 Loss of Rb proteins causes genomic instability in the absence of mitogenic signaling \\ Tanja van Harn, Floris Foijer, Marcel van Vugt, et al. \\ Genes Dev. July , 2010 24: 1377-1388}

References This article cites 41 articles, 20 of which can be accessed free at:

http://genesdev.cshlp.org/content/24/13/1329.full.html\#ref-list-1

Articles cited in:

http://genesdev.cshlp.org/content/24/13/1329.full.html\#related-urls

\section{License}

Email Alerting
Service

Receive free email alerts when new articles cite this article - sign up in the box at the top right corner of the article or click here.

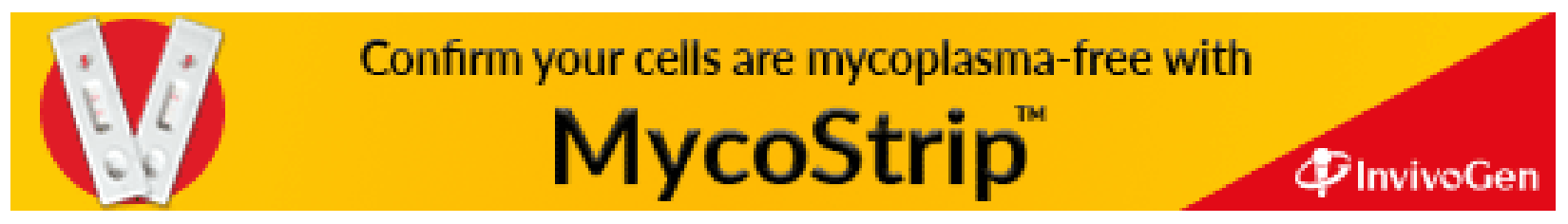

